\title{
NOTES
}

\section{Morphology of Sulfonated Random Ionomers Based on Hydrogenated Styrene-Butadiene Copolymer Studied by SAXS}

\author{
Joon-Seop Kim, ${ }^{\dagger}$ Mitsuo Nishida, ${ }^{*}$ and Adi EISENBERG** \\ Department of Polymer Science \& Engineering, Chosun University, Kwangju 501-759, Korea \\ * Polymer Technical Center, Toyobo Co., Ltd., Ohtsu, Shiga 520-0243, Japan \\ ** Department of Chemistry, McGill University, Montreal, Quebec, H3A 2 K6 Canada
}

(Received March 30, 1998)

\begin{abstract}
KEY WORDS Morphology / Small-Angle X-Ray Scattering / Ionomer / Styrene-Butadiene / Ionomer Peak / Hydrogenation /
\end{abstract}

During the past three decades, extensive studies have been performed to improve our understanding of the morphology and properties of ionomers. It is generally accepted that ionic groups form aggregates, called multiplets. ${ }^{1}$ The Eisenberg-Hird-Moore (EHM) model, a recent model of the morphology of random ionomers, postulates that polymer chains surrounding the multiplets undergo reduction in mobility. ${ }^{2}$ At very low ion content, only multiplets are present. As the number density of the multiplets increases with ion content, the regions of restricted mobility start to overlap and form large contiguous regions of reduced mobility. When the dimensions of these regions exceed $c a .100 \AA$, they are called clusters. ${ }^{2}$ In this state, the ionomer exhibits two glass transitions: one for the matrix regions is found at lower temperatures, while that for the cluster regions is located at higher temperatures.

In general, clustered ionomers exhibit small-angle peaks in small-angle X-ray scattering (SAXS) profiles. The poly(styrene-co-cesium methacrylate) ionomer containing $\mathrm{ca} .7 \mathrm{~mol} \%$ of ions exhibits the maximum in the SAXS peak at $q=c a$. $0.32 \AA^{-1}(q=4 \pi \sin \theta / \lambda$, where $\theta$ is half the scattering angle and $\lambda$ is the $\mathrm{X}$-ray wavelength) ${ }^{3}$ $q$ corresponds to a Bragg spacing $\left(d_{\mathrm{Bragg}}\right)$ of $c a .20 \AA$. Bragg spacing is thought to reflect the distance between multiplets. ${ }^{4,5}$ The poly(styrene-co-cesium styrenesulfonate) ionomer ( $c a .5 \mathrm{~mol} \%$ of ions) shows the maximum of the SAXS peak at $q_{\max }=c a .0 .15 \AA^{-1}\left(d_{\mathrm{Bragg}}=c a\right.$. $42 \AA) .{ }^{6}$ Another interpretation of the SAXS profile, the so-called core-shell model, has also been proposed. ${ }^{7}$

The dynamic mechanical properties of sulfonated poly(styrene-co-ethylene-co-butylene) (SPSEB) random ionomers have been investigated. ${ }^{8}$ Thus, as a follow-up work, the present study explores the morphology of the SPSEB ionomers. The comparison of the results obtained in this study with those from the sulfonated polystyrene ionomers is also made. Among the results obtained in the present study, the answers to the following two questions are of most importance; 1) what type of morphology does this ionomer system have? 2) what is the effect of the matrix $T_{\mathrm{g}}$ on the multiplet formation?

\footnotetext{
$\dagger$ To whom correspondence should be addressed.
}

\section{EXPERIMENTAL}

\section{Polymer Synthesis}

The preparation and sulfonation of a hydrogenated poly(styrene-co-butadiene) random copolymers, i.e., poly(styrene-co-ethylene-co-butylene) (PSEB), are described elsewhere. ${ }^{8}$ The PSEB copolymer is composed of $73 \mathrm{~mol} \%$ of ethylene, $8 \mathrm{~mol} \%$ of butylene, and 19 $\mathrm{mol} \%$ of styrene. The polymer was sulfonated using a modification of the sulfonation method of Thaler. ${ }^{9}$ The sulfonation level was determined by titration of the sulfonated PSEB (SPSEB) sample with standard methanolic $\mathrm{NaOH}$ to the phenolphthalein end point.

\section{Sample Preparation}

The copolymers were dissolved in a mixture of xylene/1-butanol $(3 / 1 \mathrm{v} / \mathrm{v}$, for ionomers of low ion contents) or in a mixture of methanol/tetrahydrofuran $(1 / 1 \mathrm{v} / \mathrm{v}$, for ionomers of high ion contents) to give a $5 \%$ $(\mathrm{w} / \mathrm{v})$ solution. A predetermined amount of methanolic $\mathrm{CsOH}$ or $\mathrm{NaOH}$ was added to neutralize the acid groups. The solutions were freeze-dried and dried further under vacuum at $160^{\circ} \mathrm{C}$ for one day. The powder samples were compression molded at $240^{\circ} \mathrm{C}$ under a pressure of $c a$. $20 \mathrm{MPa}$. The molded samples took the form of a thin disk with approximate dimensions of $12 \mathrm{~mm}$ (diameter) $\times$ $1 \mathrm{~mm}$ (thickness). Notation for the ionomers is SPSEB$x-y$, where $x$ is the type of cation and $y$ denotes ion content in $\mathrm{mol} \%$.

\section{SAXS Experiments}

SAXS experiments for the plasticized ionomers were conducted at D-22 station of the LURE-DCI synchrotron radiation source (Orsay, France). ${ }^{10}$ Fixed-exit, double-crystal monochromators were used to provide a beam of $9000 \mathrm{eV} \mathrm{X}$-rays $(\lambda=1.377 \AA)$. The size of the beam at the sample was smaller than $2 \mathrm{~mm}^{2}$. The detectors, consisting of two beam deflectors and a NaI scintillator, were positioned before and after the sample chamber to monitor the relative input of the X-ray intensity and the sample absorption. A one-dimensional position-sensitive detector, filled with $\mathrm{Xe}-\mathrm{CO}_{2}$ gas, with a resolution of $200 \mu \mathrm{m}$ was used to detect scattered X-rays. The sample-to-detector distance of $570 \mathrm{~mm}$ allowed SAXS data to be obtained in the $q$ range from ca. 0.012 to $0.32 \AA^{-1}$. The SAXS data were plotted as 


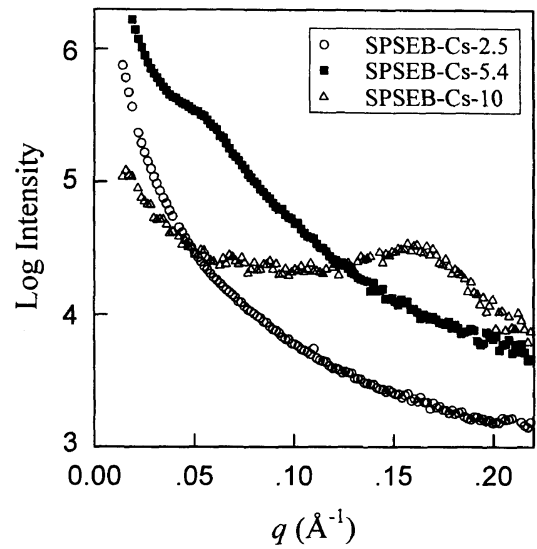

Figure 1. SAXS profiles plotted as intensity vs. $q$ for cesium neutralized ionomer samples containing $2.5,5.4$, and $10 \mathrm{~mol} \%$ of ions.

Table I. $q_{\max }$ and $d_{\mathrm{Bragg}}$ values for the SPSEB ionomers

\begin{tabular}{lcc}
\hline \multicolumn{1}{c}{ Sample } & $q_{\max } / \AA^{-1}$ & $d_{\text {Bragg }} / \AA$ \\
\hline PSEB & No peak & - \\
SPSEB-Cs-0.5 & No peak & - \\
SPSEB-Cs-2.5 & No peak & - \\
SPSEB-Cs-5.4 & 0.055 & 114 \\
SPSEB-Cs-7.7 & 0.100 & 63 \\
SPSEB-Cs-10 & 0.163 & 39 \\
SPSEB-Cs-15 & 0.174 & 36 \\
SPSEB-Na-0.5 & No peak & - \\
SPSEB-Na-1.8 & 0.089 & 71 \\
SPSEB-Na-5.4 & 0.112 & 56 \\
SPSEB-Na-7.7 & 0.122 & 52 \\
SPSEB-Na-18 & 0.160 & 39
\end{tabular}

relative intensity $v s . q$ after correction for background scattering. All samples were normalized to a thickness of $1 \mathrm{~mm}$.

\section{RESULTS AND DISCUSSION}

As expected, no SAXS peak was seen for the nonionic PSEB sample (not shown here). Selected SAXS data for the $\mathrm{Cs}^{+}$-neutralized ionomers containing 2.5, 5.4, and $10 \mathrm{~mol} \%$ of ions are shown in Figure 1. The SPSEBCs-2.5 sample also fails to show a SAXS peak, probably due to the low ion content. When ion content was increased to $5.4 \mathrm{~mol} \%$, the sample started to show a SAXS peak. In the figure, it is seen that with increasing ion content, the SAXS peak intensity increases, while its position shifts to higher $q$. The Bragg distances calculated from the $q_{\max }$ of the peak maximum are $c a .114$ and $39 \AA$, for the 5.4 and $10 \mathrm{~mol} \%$ samples, respectively. $q_{\max }$ and the calculated Bragg distances for all ionomers studied here are listed in Table I. Naturally, with increasing ion content, the size and number of multiplets increase, resulting in decrease in Bragg spacing.

Figure 2 shows selected SAXS profiles for sodium neutralized samples. Surprisingly, a SAXS peak is seen even at a low ion content, i.e., in the SPSEB-Na-1.8 sample. Since the $\mathrm{Na}^{+}$ion is smaller than $\mathrm{Cs}^{+}$ion $(1.02-1.24 \AA$ vs. $1.74-1.88 \AA),{ }^{11}$ the electrostatic force is stronger for the Na-sulfonate ion pair than for the Cs-sulfonate ion pair. Thus, it is probably much easier for the Na-sulfonate ion pair to form multiplets than

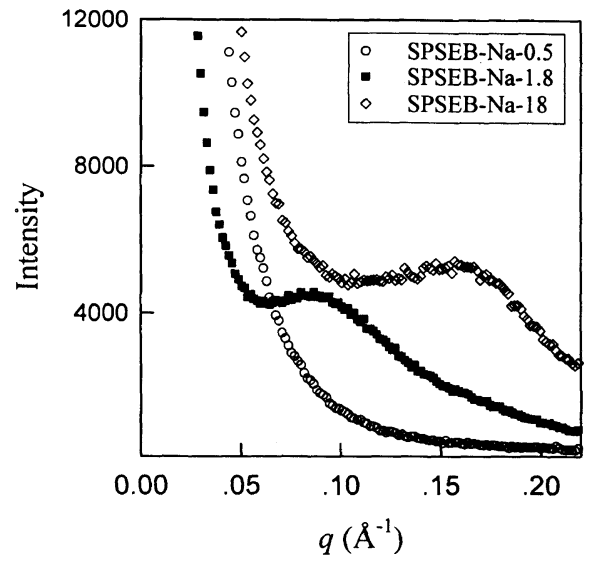

Figure 2. SAXS data for sodium-neutralized ionomer samples with different ion content.

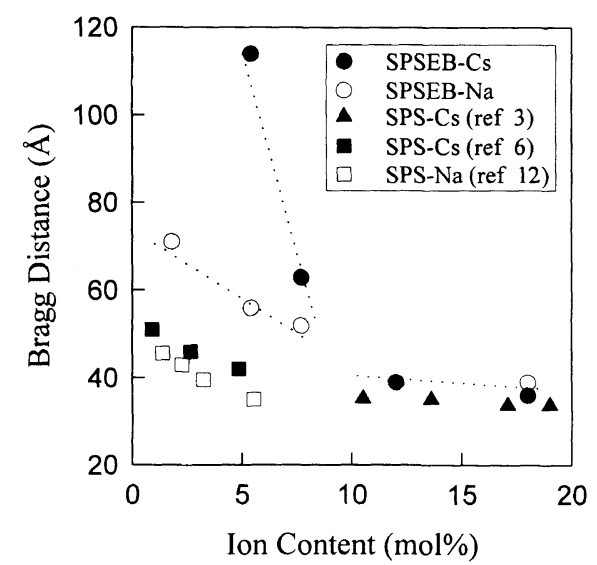

Figure 3. Bragg distance as a function of ion content for the sodium and cesium neutralized SPSEB and SPS ionomers.

Cs-sulfonate ion pairs. The $\mathrm{Na}^{+}$-neutralized ionomer containing as low as $1.8 \mathrm{~mol} \%$ of ions should thus show an SAXS peak. The position of a peak maximum shifts to higher $q$ with ion content; thus, $q_{\max }$ 's are $c a .0 .089$ and $0.160 \AA^{-1}$ for the SPSEB-Na-1.8 and the SPSEBNa-18 samples, respectively. The calculated Bragg distances for the above samples are 71 and $39 \AA$, respectively.

The Bragg distances obtained in the present study together with those of sulfonated polystyrene ionomers $^{3,6,12}$ are shown in Figure 3 as a function of ion content. The figure shows that at low ion contents, the average intermultiplet distance of the SPSEB ionomers decreases with ion content. Even though there are only a few data points, it seems clear that at low ion contents the distance decreases more rapidly for the cesium samples than for the sodium samples. This difference is probably due to the strength of ionic interaction, which is weaker for cesium-sulfonate than the sodium-sulfonate ion pair. Thus, at low ion content, Na-sulfonate groups can form more multiplets than the Cs-sulfonate, resulting in smaller Bragg distance for the Na-sulfonate ionomers at comparable ion content. Above $c a .10 \mathrm{~mol} \%$ of ions, the type of cation seems to affect the morphology of ionomer less strongly, and thus Bragg distance does not appear to change significantly with ion content. In the dynamic mechanical study of the SPSEB-Na system, Nishida and Eisenberg found that the phase-inversion 
point beyond which cluster regions become dominant relative to the matrix regions, occurs at $c a .7 \mathrm{~mol} \%$; above $10 \mathrm{~mol} \%$ of ions, the volume fraction of the cluster regions does not change significantly with ion content. ${ }^{8}$ From this, along with morphological data above, it can be concluded that when clustering is well-developed, scattering centers are also fully developed, and thus Bragg distance does not change significantly with ion content. Similar observations have also been made in the poly(styrene-co-methacrylate) ionomer system. ${ }^{3,13}$

It is interesting to note the Bragg distance of the SPSEB ionomers of high ion contents is similar to that in the sulfonated polystyrene ionomers (SPS) (Figure 3). At this point, it should be recalled that the type (Cs-sulfonate) and position of the ionic group (para-position of the benzene ring of a styrene unit) are the same in these two ionomers. Therefore, both ionomers should have comparable steric effect on the multiplet formation; similarity in the morphology is observed as a result. However, it should also be pointed out that the polymer unit in the regions surrounding the multiplets is mainly ethylene for SPSEB ionomers, while styrene for sulfonated polystyrene ionomers. Thus the similar Bragg spacing found in those two ionomer systems may indicate that the distance is probably the intermultiplet distance preferred by ionomers which have sulfonate groups attached directly to the para-position of the benzene ring.

Acknowledgment. This work was partly supported by the Natural Sciences and Engineering Research Council of Canada (NSERC).

\section{REFERENCES}

1. A. Eisenberg, Macromolecules, 3, 147 (1970).

2. A. Eisenberg, B. Hird, and R. B. Moore, Macromolecules, 23, 4098 (1990)

3. M. Jiang, A. A. Gronowski, H. L. Yeager, G. Wu, J.-S. Kim, and A. Eisenberg, Macromolecules, 27, 6541 (1994).

4. D. J. Yarusso and S. L. Cooper, Macromolecules, 16, 1871 (1983).

5. R. B. Moore, D. Bittencourt, M. Gauthier, C. E. Williams, and A. Eisenberg, Macromolecules, 24, 1376 (1991).

6. J. J. Fitzgerald and R. A. Weiss, J. Polym. Sci., Part B, Polym. Phys., 28, 1719 (1990).

7. W. J. MacKnight, W. P. Taggert, and R. S. Stein, J. Polym. Sci., Polym. Symp., 45, 113 (1974).

8. M. Nishida and A. Eisenberg, Macromolecules, 29, 1507 (1996).

9. W. Thaler, Macromolecules, 16, 623 (1983).

10. J. M. Dubuisson, J. M. Dauvergne, C. Depautex, P. Vachette, and C. E. Williams, Nucl. Instrum. Methods Phys. Res., A246, 636 (1986).

11. H. T. Evans, Jr., in "CRC Handbook of Chemistry and Physics," D. R. Lide, Ed., CRC Press, Boca Raton, FL, 1996, pp 12-14.

12. R. A. Weiss and J. A. Lefelar, Polymer, 27, 3 (1986).

13. J.-S. Kim, R. J. Jackman, and A. Eisenberg, Macromolecules, 27, 2789 (1994). 